\title{
DRAWING TECHNIQUES ON THE DESIGN CONCEPT PHASE: AN ANALYSIS OF BRAZILIAN, JAPANESE AND TURKISH STUDENTS' STRATEGIES
}

\author{
Cristina TORREZZAN ${ }^{1}$, Julio VAN DER LINDEN ${ }^{1}$, Erik BOHEMIA², Pinar KAYGAN ${ }^{3}$, \\ Mauricio BERNARDES ${ }^{1}$ \\ ${ }^{1}$ Universidade Federal do Rio Grande do Sul - UFRGS \\ ${ }^{2}$ Academy of Design Innovation Management - ADIM \\ ${ }^{3}$ Middle East Technical University - METU
}

\begin{abstract}
Professionals such as product designers, architects, and engineers have an intrinsic relationship with drawing, using it to represent everything from the creative sketches of a proposal to its production. In this sense, technical drawing and sketching techniques are a relevant part of design education. In this context, this article presents an analysis of drawings developed by product design students from different countries working in the Global Studio 2018, an international interinstitutional project. In this edition, undergraduate product design students from five universities from four countries (Brazil, Italy, Japan and Turkey) worked in sixteen paired teams, simultaneously playing the roles of "client" and "designer". This study deals with the work of three teams from a Brazilian university and its paired teams, one from Japan and two from Turkey. To support this study, nine categories of analysis were used: Type of drawing; Material used; Quality of the Trace; Presence of Text; Scale; Drawing Communication; Differences and similarities in the drawings of the teams of each country and between members of the same team. In some cases, students used drawings as mere illustrations for detailed textual descriptions of their design concepts. In others, they presented their design concepts by isometric drawings and frontal visions, using texts only as complementary information. The results allowed to identify how the students articulated different forms of drawing for the same purpose.
\end{abstract}

\section{Keywords: Drawing techniques, design concept, cross-cultural project, global studio}

\section{INTRODUCTION}

The disciplines of technical drawing deal with the drawing of projects, providing information about the rules and technical norms of drawing. In its pedagogical proposal it advocates contextualised teaching through the integration of theory and practice. The intention is, based on the balance between these two points, to provide students with the experience necessary to act competently in their future profession. The development of skills related to graphic expression is even more relevant in design, architecture and engineering courses, which have drawing as their main means of communication. In this sense, it is opportunity to carry out studies that collaborate with the elaboration of educational practices that support the teaching and learning process of the students.

In this context, this article presents an analysis of the graphic strategies used by teams of design students from Brazil, Turkey and Japan at the conceptual design stage. It was carried out through an international exchange among undergraduate subjects, members of the Global Studio project. This, in turn, aims to investigate how multidisciplinary and cross-cultural issues are addressed by universities in different countries. The activities developed in this project adopt a pedagogical dynamic based on problem situations analogous to those that students will find in their future professional practice [1]. This investigation was not carried out in a specific discipline of technical drawing, but in others, located in the final semesters of the course, in which students will need to articulate the already studied knowledges (among them the technical drawing) to solve the challenges.

Therefore, the objective was to verify how the students used the drawing to communicate and express their ideas throughout the development of the conceptual design stage. Based on the obtained results, it is intended to collaborate with the elaboration of educational practices that support the development of 
graphic expression skills in the courses of design, architecture and engineering. To do so, the following sections will discuss the main concepts involved in this study, the methodology used and the results.

\section{THE TEACHING OF TECHNICAL DRAWING}

The drawing can be considered a form of language, necessitating, therefore, a proper grammar, spelling and calligraphy [2]. In the case of the technical drawing (TD), focus of this study, these elements are composed by the rules, conventions and norms of the technical representation of objects. This is because, unlike artistic drawing, which can express the same object in different ways and styles, or even allow different interpretations before the same work, the technical drawing needs to represent a certain object always in the same way, clearly, completely and precise, without the possibility of ambiguity in its interpretation. This rigidity is necessary because of its intended purpose. The technical drawing is used to represent objects to be fabricated. In this way, its elements are applied from the stage of planning, representation to detailing and execution of a given object. Throughout this process, it needs to express information, for example: the objective that the object proposes to fulfil, the place to be occupied, the efforts supported, the forms and dimensions adopted, and the material used. The minimum fragility in the representation of one of these information's may cause errors that will propagate in the successive stages of the project and its execution. In addition, these steps are increasingly being carried out by professionals and companies, even multinational companies, making the need for rigidity in the representation of the technical drawing even more evident.

However, the teaching and learning process of technical drawing content has a certain complexity. This is because objects are not always portrayed in the same way they are viewed by the observer. Sometimes the expression of reality would be so time-consuming and complex that the use of symbolic drawing is indicated, in which a series of specific and normative technical rules and standards need to be followed. In other situations, different projection systems from those in human vision are used, such as in the planning of the orthographic views, requiring the mastery of a new representation logic. The difficulties found in this process generate failures in the interpretation of the object, hindering the idealisation and realisation of interventions and even the creative process - the student's difficulty in representing what he imagines and in imagining what is represented. At the same time, the discipline of technical drawing is usually given at the beginning of the courses, sometimes not allowing, in this first moment, the student to understand its importance and applicability in professional functions. This fact helps them find even greater difficulty in appropriating said content, only realising its applicability years later, when they need to apply it in professional functions.

In recent years, digital tools and CAD (Computer-Aided Design) programs have provided new possibilities in the scope of teaching and drawing up the technical drawing. In this sense, from the teacher's point of view, digital animations, learning objects and virtual learning environments (VLE) have been increasingly integrated into educational practices. These resources not only favour the expansion of the physical environment of the classroom, but also provide actions previously hampered by financial and temporal issues. In the area of technical drawing, these digital tools enable virtual demonstrations, animations, simulations, which in turn support the process of visualising objects, their planning, manipulation and practical application, for example. With regard to students and professionals, the use of CAD programs promotes faster, more detailed and accurate drawing (2D and 3D), which can be stored, modelled, shared, modified and easily used. This innovation, increasingly inserted in academic and professional daily life, implies a greater responsibility to the teaching of technical drawing - to emphasise that the tool will not draw for the professional, that is, the creative agent continues to be the designer / draftsman, only with a larger "pencil". In particular, the dissemination of the use of 3D modelling programs and printers (both in the ascendancy), is collaborating with the emergence of new techniques of creation and demonstration of objects. Over time, these innovations can be incorporated into the classroom in order to innovate, or at least to add to the practice of technical drawing.

In the courses of design, engineering and architecture, the domain of technical drawing is fundamental, because it will be through them that these professionals will express their creations or interventions regarding objects (products, buildings, among others). Possible deficits in drawing ability will cause damage in this creative process [3], since they need to provide a visual sense to complex concepts [4]. It happens that, more and more, students who have good concepts in their academic life but who find it difficult to work in the job market are visualised. This is because they dominate content but cannot mobilise it in solving professional needs and challenges. In this way, the importance of the integration 
between knowledge (to know), skills (know-how) and attitudes (knowing to be) is approached from the academy. In reality, these elements act in an integrated way. This separation is only scientific, in order to allow a better analysis on them. From it, the teacher finds the opportunity to identify at what point can best help each student. One possible way to contemplate these elements in the classroom is through the proposition of problem situations, in which students will need to apply the contents studied in the search for solutions.

In this scenario, the present article analyses drawings by product design students from different countries who worked on the Global Studio 2018 project, through the exchange of undergraduate courses in Design in Brazil, Turkey and Japan. The objective is to visualise the drawing resources used by the students, in order to collaborate in the elaboration of innovative educational practices.

\section{ANALYSIS OF THE DRAWING TECHNIQUES USED BY STUDENTS OF THE GRAPHIC DESIGN COURSE OF BRAZIL, TURKEY AND JAPAN DURING THE CONCEPT DESIGN PHASE}

The present study analysed the drawings developed by students of the design course that participated in the Global Studio 2018 project, through the exchange between disciplines of universities in Brazil, Turkey and Japan. Following the methodology of this project, they worked in paired groups: two groups Brazil-Turkey and one Brazil-Japan. Thus, they acted both as designers - proposing solutions for the brief received, as well as clients - exposing a need of their city to be supplied. The subject covered was public transportation. Twenty-two undergraduate students participated, and the activities were carried out in 10 weeks.

\subsection{Global Studio Project}

Global Studio is an international and cross-cultural collaborative project involving different countries. Its purpose is to investigate how design education in different universities is addressing the multidisciplinary and cross-cultural profile of the work environment. In its methodology, it integrates students of the Product Design course from different countries, who work in paired groups. Thus, they perform the dual activity of client and designer, requesting and proposing design projects from a needs plan. Through this practice, participants, still graduating, find the opportunity to articulate the concepts studied in the resolution of problem situations (cases). These are similar to those they will find in the future job market, with the differential of also involving different cultural issues.

\subsection{Data Collection Process}

The objective was to observe how the students used the drawing throughout the process of elaboration of the conceptual design of the proposed product. Thus, 9 categories of analysis were used: (1) Type of drawing (views or perspective); (2) Material (computer, pencil, pen, use of colours); (3) Trace quality (thickness difference, parallelism between lines, tracing definition); (4) Presence of text (presentation form); (5) Scale (proportion to the different elements of the drawing); (6) Communication of the drawing (if sufficient to understand the elaborated proposal); (7) Differences and similarities in the drawings of the teams of each country and between members of the same team; (8) Differences and similarities in the drawings of the teams of each country and between members of the same team and (9) Semester in which the students are. The drawings posted on the blog of each group were analysed.

\subsection{Analysis of Drawings}

In order not to expose the students participating in this study, the teams are identified by codes: Team 5 and Team 6 (Turkey); Team 11, Team 12 and Team 16 (Brazil); and Team 14 (Japan).

\subsubsection{Turkish teams}

Team 5 developed a product to assist the access of elderly, pregnant and disabled people in buses in Brazil, following the brief elaborated by Team 11. They used the isometric perspective and common orthographic views, predominating the use of freehand sketch with colour application, using drawings in CAD software only in the presentation board. Participants use the same type of drawing (sketches in perspective), with similar graphic expression and good to moderate quality. It presents a good, regular and expressive tracing in the drawing by hand, but there are deficiencies, mainly of thickness hierarchy, in CAD drawings. It uses a lot of texts, without following or approaching technical standards. In fact, it seems to use the drawings as illustrative images. The scales and proportions are respected and, 
considering all the drawings, it can be affirmed that they were able to communicate the proposal made, although the drawings are dependent on the textual information.

Team 6 created a product to store bicycles in a public place in Brazil, attending the brief elaborated by Team 12. They represent the drawings through common orthographic views and perspectives: oblique, isometric and conical. There is a predominance of drawings made in CAD software, although they also present sketches made by pen with the use of colours. They seem to use the computerised drawing to fill a gap in the drawing by hand. The textual information, of a complementary nature, is presented through multileader, following the technical format. There are irregularities in the representation of the proportion between some elements of the product created. Nevertheless, it communicated in a satisfactory way, through the drawings, the product created.

It is possible to see opposition in the quality of the traces and in the predominance of the drawing by hand or computerised. However, both use perspectives and orthographic views to represent their proposal. In Figure 1, it is possible to see some drawings of these two teams.

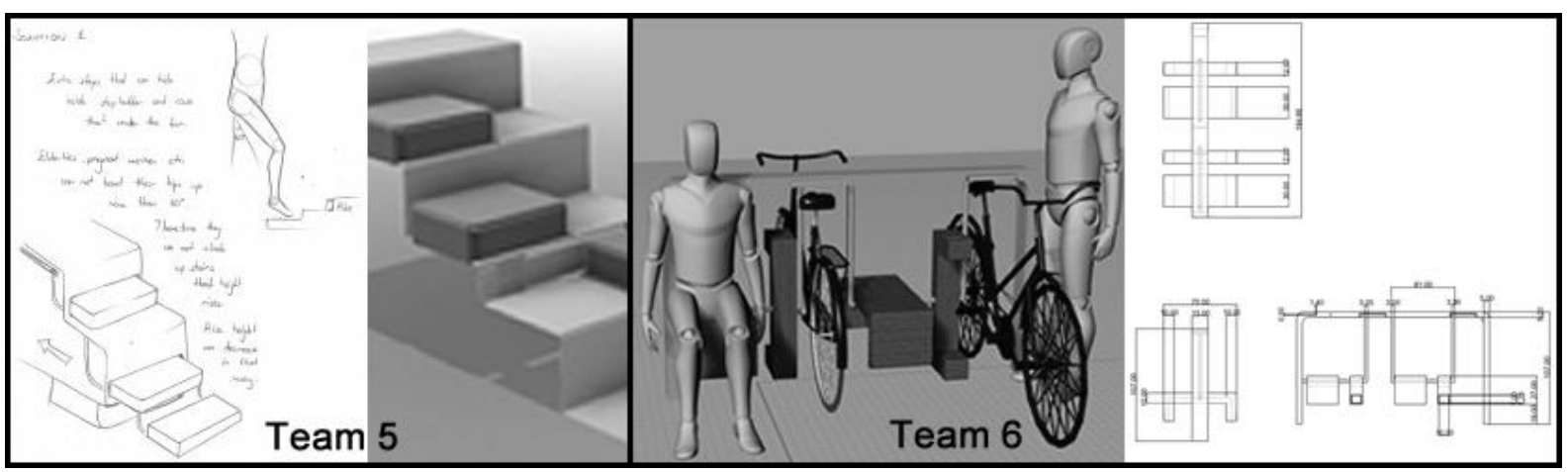

Figure 1. Turkish Teams 5 and 6 drawings

\subsubsection{Brazilian teams}

Team 11 created a portable snow sliding product based on the brief elaborated by the Team 5 . In the process of graphic representation, they used isometric perspective and common orthographic views. There was a predominance of sketches, using pencils, pens and colours. In the presentation board they used CAD drawings. In the sketches, one can notice a standard tracing between the drawings, predominating the narrow trace, with no hierarchy of thicknesses and sometimes some "hairy" and irregular traces. The same lack of graphic expression is transferred to the CAD drawings, all drawn in the same thickness. There are also some technical errors such as "upside down" dimension numbers and dimension lines that merge confusingly with the edges of the object, precisely because of the lack of difference between the thicknesses. They use a lot of textual information, so that the drawing conquers an illustrative character. They were able to communicate their proposal, but through drawings dependent on textual explanations.

Team 12 designed a device for payment on public transport in Turkey, attending the brief elaborated by Team 6. They used orthographic views and isometric and exploded perspectives. They presented freehand sketches, others by instrument, all in pen, using colour to highlight even the creation of a caption. They complemented their drawings with a 3D modelling of the prototype on the computer. It is noticed, among the members of the team, a pattern of tracing and of excellent quality. Expressive drawings, very detailed and following the technical norms of representation. The textual information is very small, of a complementary nature and according to the standard. They respected the scale and proportions and communicated all the necessary information for the manufacture of the elaborated product, including demonstrating its fittings and details through detail and assembly drawings.

Team 16 designed an application to assist the elderly in public transportation aimed to Japan, attending the Team 14 brief. This team produced few drawings in relation to the others. They used sketches in isometric perspective to contextualise the application of the application and orthographic views (wireframe). It can be seen the use of pen sketches, colours and drawings in image editing software. Good expressivity in the overall result of the drawings. But the tracing, individually, presents irregular parts, lines with lack of parallelism and some simplistic views. They used texts but tried to follow a technical standard. Regarding interface design, it achieved good visual communication through drawing, but did not address the technical drawing effectively. 
As a result, it is verified that in the Brazilian groups there is a more homogeneous alternation between the use of drawing by hand (with or without instruments) and in the computer. Again, the use of isometric perspective and common orthographic views for the exposition of the proposals can be visualised. One group, in particular, stands out for the quality of the tracing and detailing of its object, being the only one to approach the exploded perspective to show fittings and assemblies. Some drawings of these teams can be seen in Figure 2.

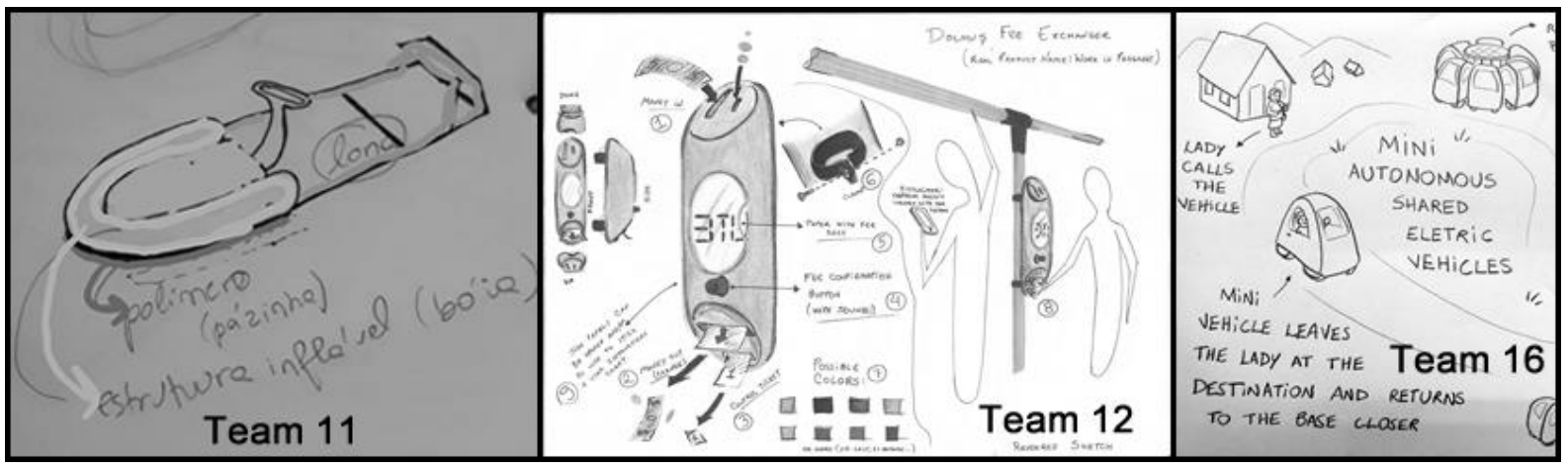

Figure 2. Brazilian Teams 11, 12 and 16 drawings

\subsubsection{Japanese team}

Team 14 designed an application to increase the safety of bus users as they wait near a safe bus stop to be used in Brazil, attending the Team 16 brief.

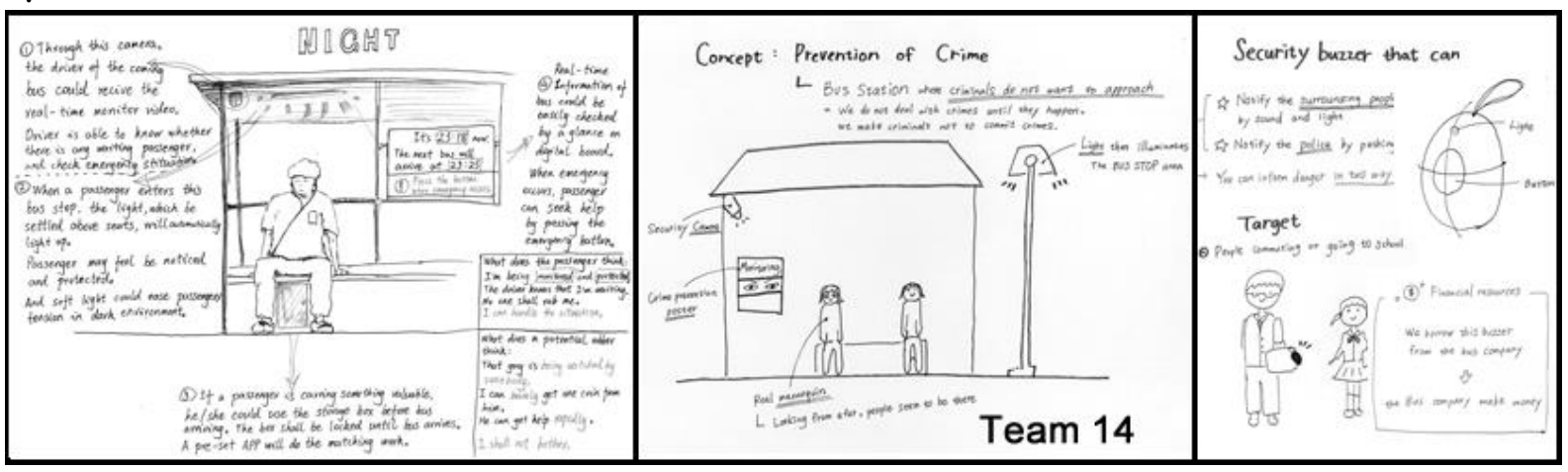

Figure 3. Japanese Team 14 drawings

There is a predominance of the use of orthographic views by pen and colours. It shows a simplistic and childlike tracing that does not seem to apply knowledge or experience in technical drawing. It uses enough textual information, so that the drawing obtains an illustrative character. The drawings are presented in isolation, as images, without using the scale and proportion reference. In this way, it can be seen that the drawings (next to the texts) explain the concept of the proposal, but there is little information about its constitution.

\subsection{Interpretation of collected data}

From the analysis of the drawings of the participating groups, it was verified that basically, independently of the country, the groups used as strategy the use of sketches in perspective during the creative process and of "negotiation" of the ideas proposed with their client. Once defined, the design concept was recorded on boards drawn in CAD software and with a more technical presentation (common orthographic views, details and dimensions). This strategy, as a whole, proved to be efficient, since it gave rise to good proposals, graphically expressed satisfactorily. However, in general, with a rare exception, it is visualised that the quality of the tracings and the mastery of the techniques of drawing and technical standards are not compatible with the advanced period in which the students are in their design courses. One of the hypotheses is that the technical drawing disciplines are generally taught at the beginning of undergraduate courses, without students having the motivation or opportunity to continue practicing the tracing and applying the technical norms in activities of other disciplines during the course. It is then necessary to investigate the causes of these inconsistencies in the development of graphic expression. Thus, it will be possible to elaborate educational practices, even 
multidisciplinary ones, that stimulate and provide the constant practice of drawing in the courses of design, architecture and engineering, because it is the development of a fundamental skill to these future professionals.

\section{FINAL CONSIDERATIONS}

The present study investigated the graphic strategies used by product design students from Brazil, Turkey and Japan in the design concept phase. For that, the techniques of drawing applied in the materials elaborated by 6 participating teams were analysed. It was possible to visualise a standard strategy, common to the different countries that integrated this practice. All groups used creative sketches in perspective and then presented the concept of design on boards with orthographic views, dimensions and other technical information. However, there was a general lack of graphic expression of the drawings, especially in perspective sketches. It is therefore necessary to continue this study, in order to investigate the possible causes of the inconsistencies found, in order to collaborate in the creation of educational practices that support the constant development and improvement of the technical drawing. It is intended to contribute to the development of educational practices that support the development of graphic expression skills in in courses such as product design, architecture and engineering, where graphic expression is the main means of communication between the subjects involved.

\section{REFERENCES}

[1] Hong B B., Bohemia E., Neubauer R. and Santamaria L. (2018) In Proceedings of EP\&DE 2018, the $21^{\text {th }}$ International Conference on Engineering and Product Design Education

[2] Cunha L.V. (2010) Desenho Técnico. Lisbon: Fundação Calouste Gulbenkian.

[3] De Vere I., Melles G. and Kapoor A. Sketchfest: emphasising sketching skills in engineering learning. In (E\&PDE12): Proceedings of the 14th International Conference on Engineering \& Product Design Education. Belgium, 2012. P. 443-448.

[4] Gabriele S. Design Inquiry Through Making. In ICDC: Proceedings of the Fifth International Conference on Design Creativity. UK, 2018. P 362-368. 